\title{
Psicoterapia de Apoyo en Atención Primaria
}

\author{
María del Prado Ordóñez Fernándeza
}

\begin{abstract}
a FEA de la Unidad de Salud Mental del Hospital General de Ciudad Real.
\end{abstract}

\section{Dirección para}

correspondencia:

María del Prado Ordoñez

Fernandez.

C/ Alarcos $N^{\circ} 3,1^{\circ} \mathrm{D}$

13001-Ciudad Real. E-mail: mpordonez@sescam.jccm.es

Recibido el 11 de junio de 2008.

Aceptado para su publicación el 30 de julio de 2008.

\begin{abstract}
RESUMEN
La terapia de apoyo en Atención Primaria tiene como meta fundamental la atenuación de ansiedades y el aumento de las defensas con el fin de mejorar el funcionamiento individual o retornar al funcionamiento previo, evitando el desentrenamiento en habilidades adquiridas, fomentando la autonomía y el contacto con la realidad. No es necesaria la motivación previa para el cambio como en el resto de las psicoterapias. El período de tiempo puede ser limitado o no según el tipo de paciente. La visita periódica cada 2-3 meses, o incluso a demanda del propio paciente, puede cubrir los objetivos. La inclusión de psicofármacos serviría para reforzar el trabajo de soporte, permitir la continuación del vínculo durante los intervalos de las visitas y como evaluador de la mejoría del paciente.
\end{abstract}

Palabras clave: Psicoterapia. Atención Primaria de Salud.

\section{ABSTRACT}

\section{Psychotherapy Support in Primary Care}

The main goal of psychotherapy support in primary care is to reduce anxiety and to strengthen the defenses in order to improve the individuals' performance or enable them to return to a previous performance, preventing skills acquired from being lost, increasing independence and the contact with reality. Prior motivation for the change, needed for other psychotherapies, is not required. The period of time may or may not be limited depending on the type of patient. A regular visit every 2-3 months, or even at the patient's demand, may fulfil objectives. The inclusion of psychotropic drugs would help to reinforce the support work, permitting the connection to be maintained in the intervals between visits and also enabling improvement in the patient to be evaluated.

Key words. Psychotherapy. Primary Health Care.

\section{INTRODUCCIÓN}

Durante los años en los que trabajé como Especialista de Área en el Centro de Salud de Móstoles, llevé a cabo la coordinación con el Equipo de Atención Primaria de nuestro Distrito (Azorín) y resultó una tarea sencilla y gratificante por la riqueza humana del equipo. De estos encuentros quincenales aprendimos muchas cosas y aún recuerdo la enorme carga asistencial que el equipo soportaba. Esta sobrecarga no daba mucha cabida a la formación continuada y en especial a la actualización en los conocimientos (exigencia deontológica y legal para todos los profesionales).

Actualizarse en cardiología, neumología, neurología, psiquiatría, medicina interna, etc., implicaba demasiadas lecturas para ser asimiladas.

Los médicos de atención primaria conocían la importancia que jugaban los factores psicológicos en la práctica médica, en el día a día de su ejercicio, y me animé a resumir para ellos a los dos autores que desde mi punto de vista resultaban más sencillos, claros, profundos, y sobre todo clínicos: M. Balint y J.L. Tizón García. El resumen, por supuesto, no aportaba ninguna idea original a la de los autores e incluso utilicé frases textuales por no encontrar una forma más correcta y sencilla para expresarlo.

A principios de 1998, desde Atención Primaria se solicitó a los psiquiatras del Servicio (Servicio de Psiquiatría del Complejo Hospitalario de Ciudad Real) la participación en los seminarios de formación continuada, y curiosamente uno de los temas solicitados llevaba por título: psicoterapia en Atención Primaria. Me ofrecí voluntariamente a exponerlo, y volví a experimentar la enorme acogida que tienen estas cuestiones entre los médicos de cabecera. Al fin y al cabo son ellos los que continuamente es- 
tán manejando los componentes psicológicos en la práctica diaria.

Deseo que quede constancia de que las ideas y contenidos de este artículo son transcripciones de tan excelentes maestros (M. Balint y J.L. Tizón) y pido disculpas a los mismos si algún concepto ha sido mal interpretado o mal contextualizado.

\section{FACTORES PSICOLOGICOS DE LA PRÁCTICA MÉDICA}

Frecuentemente, cuando se habla de tener en cuenta factores psicológicos en la práctica médica, muchos profesionales argumentan la imposibilidad del abordaje por la creciente demanda asistencial y el desastre asistencial, pero a menudo las "presiones" asistenciales son sentidas como más "presionantes" porque no se tiene en cuenta la posibilidad de elaborar las fantasías y temores de los consultantes, que llevarían a una mejor recepción de los mismos y a cambios en el trato personal que se les dispensa.

En ocasiones los profesionales nos sentimos desbordados por ansiedades personales provocadas por la relación asistencial. La sensación de desbordamiento, en ocasiones, proviene más de esa ansiedad no elaborada que de un real desbordamiento asistencial.

Esto no es óbice para afirmar que, realmente, la situación sanitaria en nuestro país presenta graves deficiencias. La asistencia primaria está en el límite de lo humano y de lo imposible. Pero aún así, existen experiencias de equipo que han intentado modificar la organización de su trabajo para poder considerar aspectos psicológicos y sociales y no sólo los biomédicos.

El resultado de esta mejor organización del desastre, considerando los aspectos psicológicos (fundamentalmente la escucha de los componentes psicológicos en el enfermo), en cualquier consulta típica, hace que el número de consultas disminuya. Entre otras cosas, porque un paciente más contenido en sus ansiedades no necesita tantos medicamentos, recetas, tantas visitas, etc.

Por lo tanto, a pesar del actual desorden organizativo de la asistencia primaria, es posible atender mejor a la población (Belenes, 1978-1980; Bravo, 1979; Galeote, 1986; Tizón 1981-1984; Balint, 1968; Norell, 1973; Treadway 1983), en especial si pasamos a tener en cuenta y valorar más seriamente los aspectos psicológicos.

Puesto que el paciente, como decía Balint (1968), usa a su médico para intentar tratar ansiedades y temores varios (y no sólo los provenientes de enfermedades físicas directas), el médico ha de conocer lo suficiente sobre los elementos psicológicos de la relación (ansiedades, fantasías, temores, defensas, etc.) para poder encauzar los mismos de forma positiva con respecto a la salud del paciente, de los miembros del equipo, etc. y de la propia relación asistencial.

\section{LA ANSIEDAD Y LOS MECANISMOS DE DEFENSA}

La ansiedad va a ser la emoción en todo paciente que acude a consultarnos. La vemos como sustrato y reforzador de los principales temores y esperanzas con las que los pacientes nos llegan. Es el elemento básico de lo intrapsíquico, de la vida mental del sujeto. El médico debe considerar la ansiedad como inseparable de la vida: no es posible la vida humana sin un cierto monto de ansiedad.

El psicoanálisis actual ha investigado esta importante cuestión y, para ello, ha seguido la línea fundamental en la que se halla comprometido desde hace decenios: investigar los fenómenos en la infancia, en los primeros momentos, y experiencias de la vida humana. En la medida en que la infancia es el crisol de las representaciones mentales del futuro (fantasías conscientes e inconscientes, ansiedades, emociones, sentimientos, pensamientos, deseos, recuerdos, etc.) en esa misma medida es en la infancia donde nos resultará más productivo buscar la respuesta a nuestro interrogante.

Así, a partir de las investigaciones psicoanalíticas al respecto, se piensa que, muy esquemáticamente, existen tres fuentes o peligros fundamentales para el organismo: los peligros y las ansiedades de diferenciación-indiferenciación, los peligros y ansiedades que provienen de ataques, de persecuciones, internas o externas a nuestro organismo, y, en tercer lugar, los peligros procedentes de la pérdida, el error, la culpa.

\section{Las ansiedades de diferenciación.}

En ocasiones son llamadas confusionales "primitivas". Cada dolor, frustración, pérdida, sensación molesta, puede ser vivida con una intensa confusión, en la que no se puede diferenciar bien si viene de dentro o de fuera, de los otros o de uno mismo, del propio organismo o del entorno. Cada avance en la diferenciación, cada progreso, nos va a dejar "indefensos" ante los peligros reales de no ser atendidos, de ser abandonados al dolor, al sufrimiento, a la falta de cariño, al hambre, etc. Cada nuevo paso en la diferenciación pondrá en marcha intensos grados de ansiedad. Este tipo de ansiedad se manifiesta al exterior mediante la confusión, la indecisión, las vacilaciones, la incoordinación motriz, el autismo, o negativa a establecer diferenciación.

Espontáneamente tendemos a elaborar las ansiedades de "diferenciación", de confusión primitiva, ordenando la realidad o nuestras percepciones de la misma, disociando unas perspectivas de otras, sobre todo las internas de las externas, preguntando, reflexionando, planificando, clasificando, controlando, etc., que son todas ellas actividades destinadas a organizar la realidad ("separar la luz de las tinieblas"). Gracias a la experiencia repetida de ser cuidado, de que cuando una sensación desagradable domina al bebé, "algo sucede" en su ayuda, sin que éste sepa si viene de dentro o de fuera, y gracias a que este "algo" con una serie de características regulares, no cambiantes, calma esa sensación desagradable y la ansiedad consecutiva, gracias a ese tipo de experiencias (repetida centenares de miles de veces en los primeros 
años de todos nosotros) en nuestro incipiente "mundo interno", en nuestra incipiente "realidad psicológica", van formándose las primeras regularidades.

Es fácil entender pues la necesidad psicológica que todos tenemos de poseer, en esos primeros días, meses y años, un ambiente psicológico estable: cuanto más cariñoso y regular sea ese ambiente, más fácil resultará establecer las primeras diferenciaciones entre el afuera y el adentro, entre el yo y el no-yo, entre lo mental y lo corporal. De ahí que psicoanalistas de la Sociedad Española de Psicoanálisis hayan propuesto el término "unidad originaria" para referirse a esa situación mental, fundamento de todas las diferenciaciones, en la que el bebé se siente inmerso en un círculo de relaciones no sólo basado en la madre, sino también en el padre y otros miembros del núcleo familiar, del que provienen principalmente los cuidados, el cariño, la atención, la ansiólisis, la ayuda, y otros.

\section{Las ansiedades persecutorias o paranoides}

El hecho de diferenciar un "afuera", que unas veces puede ser cuidante y otras no, que unas veces puede ser solícito y otras frustrante, que unas veces puede proteger y otras dañar (perseguir, según las profundas y dominantes fantasías de este bebé), despierta otro tipo de temores, de ansiedades: son las ansiedades basadas en la vivencia psicológica de amenaza de desintegración o desestructuración por ataque, por agresión, por esa "madre-mala" que no cuida, no atiende, en la que el bebé siente colocada no sólo la "maldad" real del no-cuidado, sino su propia maldad, agresividad, que aumenta la maldad, lo destructivo de ese "objeto malo que es la ausencia del objeto".

El origen de la tensión proveniente de esos aspectos internos destructivos, de tales ansiedades (que llamamos persecutorias o paranoides) yacerá en los ataques externos, reales, y todo no cuidado es para el niño un ataque, una persecución, o bien en la fantasía de ser atacado por causa de la proyección de la propia agresividad: mediante la actuación de ese mecanismo de defensa psicológico contra las ansiedades excesivas que es la proyección, remedio psicológico de actividades biológicas elementales (excretar lo malo, lo molesto, como las heces, alejar al perseguidor o alejarse de él, etc.), el ser humano tiende a colocar, a vivir como proveniente del exterior de sí mismo lo temido, lo agresor, lo "malo". Es a ese fenómeno humano fundamental al que llamamos proyección. Su consecuencia, como demuestra la observación clínica, es la proliferación de fantasías más o menos primitivas de haber dañado el objeto y, junto con ellas, de temores de retalización, de venganza consecutiva (Klein, 1946).

Las ansiedades persecutorias o paranoides serían pues reacciones psicofísicas ante peligros de ataques externos, ante los ataques internos (de nuestras propias representaciones mentales, por ejemplo, recuerdos vergonzosos o dolorosos), o ante el ataque del objeto sobre el que hemos proyectado nuestra agresividad $u$ hostilidad. Tales ansiedades tendemos a controlarlas, a elaborarlas mediante la precaución, la cautela, la indagación, el contraataque o la huida (la "huida psi- cológica", a través de los "mecanismos de defensa contra la ansiedad", o bien la huida externa, en la conducta), o mediante la aceptación de nuestra culpa, hasta entonces proyectada.

\section{Ansiedades depresivas}

Este tercer tipo de ansiedades son las relacionadas con la pérdida, el error, la culpa. Melania Klein las llamó así porque tienen que ver con ese tipo de vivencia, e hizo hincapié en que, a diferencia de las ansiedades persecutorias, el peligro se halla indudablemente dentro de nuestro mundo interno, el ataque proviene de nosotros mismos. Por supuesto, ello implica una elaboración suficiente al menos de las ansiedades de diferenciación o "confusión primitiva", ya que existe claramente delimitado para nosotros mismos un adentro y un afuera. También una cierta elaboración de las ansiedades persecutorias, ya que no nos sentimos tan perseguidos, ni por nosotros mismos ni por los demás, como para no poder sentir, al menos inconscientemente, nuestro error, nuestra culpa, lo que valoramos, lo perdido, etc.

Lo importante en las ansiedades "depresivas" o reparatorias es la preocupación por el objeto: por su bienestar, porque no resulte dañado o incluso por no dañarlo con nuestros propios errores, inadvertencias o ataques celosos o envidiosos. El niño acaba por percibir claramente que la fuente de sus satisfacciones, de su placer, de su gozo, está fuera de él, está en su madre, un objeto independiente, que no puede ser controlado, que puede irse y que puede gozar sin él: el objeto está en los otros, en la sociedad. Por tanto los objetos de apego, necesarios y queridos pueden irse y por la pérdida sentirse vacío, sin solución.

Las "ansiedades depresivas" van por tanto, indisolublemente unidas a esa percepción de la independencia del otro con respecto al yo y por consiguiente acarrean una ambivalencia amor-odio hacia el objeto amado porque de la misma manera que lo amamos cuando es solícito puede ser odiado cuando nos abandona, cuando no nos cuida, cuando no actúa como deseamos o necesitamos. Pero el odio hacia el objeto querido acarrea la culpa, el sentimiento de culpa por ser capaces de odiar a quien se le reconocen sus cuidados, sus desvelos, su cariño, su ternura. Por ello no hay que asociar las ansiedades depresivas con la depresión: ésta consiste no en un estado emocional sino en un cuadro clínico. Además, en la depresión (mayor o menor, neurótica o psicótica), lo que predomina no son las ansiedades depresivas o reparatorias, sino las ansiedades persecutorias insuficientemente elaboradas, que dificultarán, por tanto, la posterior elaboración de las pérdidas y de las ansiedades depresivas unidas a ellas.

\section{LA TRANSFERENCIA Y LA CONTRATANSFERENCIA}

Muchos autores en el pasado intuyeron el valor de la transferencia, pero Freud fue el primero en observar que todos los pacientes por él tratados transferían sobre él de forma inconsciente los sentimientos que anteriormente les habían unido o separado de las personas emocionalmente más significativas de su vida. 
El conjunto de experiencias mantenidas a lo largo de toda la vida, y en particular en la primera infancia, predetermina en el futuro no sólo nuestro mundo interno (el conjunto de recuerdos, fantasías, emociones, defensas, etc.) sino incluso la percepción de la realidad externa.

Este conjunto de experiencias actuará como el color del cristal con el que se mira. Pues bien, a ese fenómeno inconsciente y automático por el cual teñimos nuestra percepción del presente o del pasado con nuestras representaciones mentales y en especial con nuestros afectos, a ese fenómeno universal es al que llamamos transferencia. Y no sólo se da en los pacientes o consultantes, sino en nosotros, los profesionales: emociones, ansiedades o recuerdos que nosotros transferimos a la situación relacional.

Se suele utilizar el término contratransferencia para hablar de lo que el profesional transfiere a la relación médico-paciente, pero haciendo con ello hincapié en que se da un movimiento psicológico especular con respecto a la transferencia del paciente.

"Para poder asegurar que nuestra percepción de las emociones profundas de los pacientes es adecuada, previamente hemos de estar al menos mínimamente atentos a que no estemos transfiriendo a la misma todas las deformaciones de la percepción basada en nuestros deseos, emociones, necesidades y conflictos para que la contratransferencia no esté desviando de forma grosera nuestra percepción de la realidad del otro.

\section{RELACION MEDICO-PACIENTE}

La relación asistencial o clínica comienza bastante antes de que el consultante entre en contacto con el equipo. Habrá oído comentarios de médicos, de su forma de trabajar, de sus preferencias, de sus actitudes hacia los pacientes. Incluso en el caso de no haber escuchado nada, no por ello dejará de tener fantasías al respecto. Estas fantasías determinarán en buena medida su conducta en la entrevista clínica.

El paciente puede acudir con fantasías o esperanzas muy idealizadas, que el médico y el equipo deben procurar no fomentar, frenar y ayudar a elaborar, o puede acudir con fantasías persecutorias y temores (pacientes que han oído hablar desfavorablemente de un equipo, personalidades paranoides, etc.). Una actitud realista por parte del médico capaz de comprender estas desconfianzas y fantasías, sin reaccionar sintiéndose herido, insultado o humillado, ayudarán a que tales fantasías se vayan reduciendo en progresivas entrevistas.

De esta forma, antes de que comience el contacto directo entre el médico y el paciente ha comenzado ya la relación asistencial. Saint-Exupery comentaba en El Principito: "si vas a venir por ejemplo a las cuatro a partir de las tres comenzaré a ser feliz".

\section{ESPERANZAS DEL CONSULTANTO}

Y, ¿cuáles son las esperanzas más frecuentes del consultante?:
1. Que le libren del dolor, la incomodidad, la molestia.

2. Que le ayuden a soportar el sufrimiento.

3. Que le permitan descargarse (ansiedades y quejas).

4. Que le quieran y le traten bien.

\section{Que le libren del dolor}

El consultante busca, por supuesto, que le libren del sufrimiento, pero como todo va ligado a un grado de ansiedad y esto es transferido a la relación, muchos profesionales se sienten presionados a actuar: opinar, recetar, derivar, etc.

Las dificultades del médico para soportar la ansiedad, que en él produce la observación del dolor ajeno, puede desviarle de su papel esencial: observar, escuchar, pensar y ayudar a pensar al consultante.

El deseo y la esperanza del consultante de liberarse de sus dolores y molestias rápidamente puede entrar en colisión (complicidad inconsciente) con las dificultades del médico para soportar la ansiedad que en él produce la observación del dolor ajeno, y en especial del dolor mental (Verwoerdt, 1966). Si bien "divinum est sedare dolorem", también hay que saber o recordar que existen dolores difíciles de calmar o que, desde luego, en muchos casos antes que sedar hay que observar y explorar, incluso en el campo de las inquietudes y ansiedades que promueve la relación asistencial.

\section{Que le ayuden a soportar la carga}

Esto es frecuente sobre todo en los pacientes crónicos o terminales, o en los familiares de este tipo de pacientes. En este sentido lo más provechoso es escuchar al paciente y actuar parca y prudentemente. "Ayudando a soportar la carga estamos estimulando la parte sana del paciente y sus deseos de no dejarse hundir ante las limitaciones y la frustración". Entre la observación del enfermo y nuestras actuaciones siempre tiene que mediar la reflexión.

\section{Que le permitan descargarse}

En ocasiones lo que íntimamente desea el consultante es poder quejarse ante alguien de forma reiterada, desembarazarse de sus problemas y conflictos, contándolos, echándolos fuera, utilizándonos a veces como "cubos de la basura". En este sentido lo importante es que la escucha sirva para organizar las intervenciones desde un diálogo paciente-médico que fomente la reflexión de ambos hacia un mismo fin. La escucha reiterada, sin diálogo, no tiene ninguna finalidad terapéutica.

\section{Que le quieran y le traten bien}

Una motivación profunda de todo ser humano es la de ser querido y querer: la pulsión del amor. Durante toda la vida buscamos que nos quieran, que nos acepten tal como somos, que nos amen desinteresadamente a pesar de nuestros defectos. Todo consultante espera del equipo médico que le cuide, lo cual se halla muy cerca de la necesidad de que le quieran.

El consultante espera que le escuchen, le libremos de sus molestias, sin producirle otras nuevas, que le res- 
petemos sus defectos y limitaciones y que le tratemos bien y con cariño. Otra cosa muy diferente es que el médico o el equipo sean capaces de llenar todos estos deseos, que en algunos consultantes son muy intensos y de características infantiles.

Nuestro aprecio, que el consultante sin lugar a dudas busca, lo infiere a partir de la sensación de que le comprendemos. De ahí la favorable acogida de los médicos comprensivos en todas las épocas. Un médico comprensivo es para la mayoría de los consultantes un médico que acoge, que escucha, que aplica buenos tratamientos, con miramientos y procurando no dañar, que es cuidadoso, en definitiva, que quiere.

El peligro es tender a adoptar por hipertrofia de este rol actitudes mágicas, omnipotentes o seductoras que nos alejan de la actitud fundamental que es "pensar juntos", colocando al paciente en una posición infantil, dependiente, y al médico en un padre o madre omnipotentes, mágicos, restando autonomía al consultante que es el objetivo de toda salud psíquica.

\section{TEMORES DEL CONSULTANTE}

\section{Que le encontremos algo maligno o incurable}

Hay pacientes que ante las enfermedades se sienten dominados por ese temor (lo expresen o no). Otros, por el contrario, tienden a banalizar incluso afecciones graves. El médico ha de observar esas actitudes y expresar las dificultades de elaboración del duelo ante la pérdida de salud, o la elaboración de las fantasías con respecto a la enfermedad. Desde el respeto absoluto y la delicadeza, el médico debe ayudar al enfermo a acercarse a su propia realidad, para conjuntamente poder encontrar salidas.

\section{Que le consideremos culpable del problema}

Cuando el paciente sabe que transgrede las recomendaciones médicas (por ejemplo, fuma, ingiere alcohol, no cumple el tratamiento, etc.) acude a la consulta con intensos terrores de ser perseguido. Ello le inhibirá en la relación y hará difícil la comprensión de lo ocurrido, incluso fomentará la pelea con el equipo ("la mejor defensa contra la culpa es el ataque").

En ocasiones sentimientos de culpa inconscientes pueden conducir a deformar u ocultar información: "en mi familia y en mi trabajo toda va muy bien". Estas afirmaciones significan una invitación para que el médico no siga investigando otras causas relacionadas y se concrete en el aspecto médico o en otras relaciones ya previamente determinadas por el consultante. En sucesivas entrevistas siempre el médico debe observar la falla por donde penetrar en esas dificultades. El paciente demostrará su falla, porque desea ser ayudado, y este es el momento en que su médico debe comenzar a explorar los aspectos psicológicos implicados.

\section{Que le hagamos daño, que le castiguemos}

El temor al sufrimiento, al dolor que puede producirse en una consulta o exploración, es tan omnipresente en la práctica clínica habitual que los médicos nos hemos acostumbrado a trabajar con él y no sabemos prestarle importancia más que en los casos muy extremos.
Un posible problema es que, en la medida en que tales conductas se automaticen, lo que sale a la luz son las tendencias y actitudes profundas del médico. De ahí esa "automatización" a veces llamada "médico curtido": actitudes irónicas, despectivas hacia el sufrimiento, actitudes irónicas o brutales (mejor de repente), actitudes frías, distantes, etc.

El temor de que le lastimemos con nuestra exploración o con nuestras preguntas se puede atenuar progresivamente con la actitud honesta de la escucha, la observación, el respeto a los silencios, a la intimidad en definitiva.

\section{Que le abandonemos, que no le hagamos caso}

Otra situación relativamente frecuente en las consultas es que los pacientes se dirigen a nosotros "como si nos hicieran un favor": "Ya no quiero venir, pero como usted le dijo a mi esposa que debía verme...". Son frases que pueden expresar realidades personales o incluso muchas veces ni siquiera eso. En otras ocasiones, son siempre los aspectos más necesitados, más desvalidos, más infantiles, los que afloran. Frases de este tipo pueden ser son una solapada petición de ayuda, unida a temores, culpas y sentimientos de ser castigado.

Ciertamente, toda relación de un paciente con el médico implica un cierto grado de cesión de sus funciones y actitudes adultas, en especial cuando se trata de enfermedades graves o en trastornos de origen psicológico. Otro tema distinto es la actitud que el médico tome ante esa cesión. Una parte muy importante de la actitud médica adecuada es cuándo detenerse, cuándo poner coto a tal cesión. Cuando nos entregamos a otro de una forma más confiada se agudizan los temores a que nos abandone, nos hagan daño, no nos entiendan, etc. Este tipo de temores se encuentran siempre presentes en la relación asistencial.

En este estado regresivo, como ocurrió en la relación con sus padres en la infancia, tiende a interpretar todo lo que ocurre en la consulta como referido a él. Si el médico habla en voz baja con la enfermera ¿se referirá a él? Si le envía a otro profesional ¿no será porque ya no le interesen sus problemas y no quiere saber nada de él? Si se ríen las enfermeras mientras se le realiza una prueba ¿no se reirán de él? Por todo esto es muy importante crear en la consulta un marco invariable y protector de la intimidad, la privacidad. La clarificación al paciente de nuestras decisiones y las explicaciones sobre el motivo de cualquier tipo de actuación tenderán a reducir dichos temores y a mejorar la relación médico-paciente.

\section{ESPERANZAS DEL MEDICO}

\section{Ser útil}

Ser útil librando o ayudando a librarse del dolor, de la incomodidad, de las molestias, del temor a nuestros semejantes es la base de todo tipo de asistencia médica y la fuente de las satisfacciones profesionales fundamentales del equipo sanitario. Esta esperanza de ser útil puede sufrir una exageración que la convierta 
en nociva y peligrosa para la salud mental (del propio profesional) y para la salud del consultante.

La necesidad de asegurarse de ser útiles nos puede llevar a ser intrusivos, dar consejos: "actuar" en definitiva. Muchas veces la mejor forma de ser útiles consiste en ayudar a que el propio paciente piense y utilice sus propias posibilidades, su autonomía. Si no elaboramos la propia ansiedad de ser inmediatamente útiles, la ansiedad aumentará en cada nueva consulta, con la sensación del paciente de sentirse frustrado, al no tener un papá todopoderoso, y esto llevará a un fracaso en la relación asistencial.

Cuando damos consejos como casarse, tener un hijo, separarse, abortar, interrumpir el trabajo, ¿tenemos claro lo que representa para el paciente asumir la maternidad, la soledad, los sentimientos de culpa, etc.? ¿qué ansiedades estamos tratando, las del consultante o las nuestras propias? No olvidemos que lo que más puede ayudar a ser útiles no son nuestras orientaciones terapéuticas o consejos, sino nuestra capacidad de contención, porque en la contención estamos enseñando al otro que todo se puede contener, elaborar, e incluso cambiar.

\section{Comprender}

La comprensión se basa en la identificación introyectiva y proyectiva. En nuestro entorno y en las facultades, por desgracia, tenemos a menudo ejemplos de que es más importante saber que comprender; "brillar" que ser útiles. Un buen antídoto contra esta deformación es pensar que por muchas teorías y datos que conozcamos de los libros, esto no basta para explicar al paciente concreto, porque el término comprensión incluye aspectos afectivos y relacionales. La base de la comprensión está en la capacidad de escucha, de observación, de contención y de elaboración.

Comprender implica capacidad de esperar y por lo tanto capacidad para soportar la ignorancia, la duda, la oscuridad y la frustración durante un tiempo. El peligro es la omnipotencia en la comprensión: el profesional que se siente omnipotente en sus conocimientos o capacidad de comprensión, en general, difícilmente comprenderá al paciente.

Una expresión habitual que muestra este tipo de omnipotencia es, por ejemplo, "no hace falta que me explique nada, ya lo entiendo todo". Esta actitud mágica no tiene nada que ver con la comprensión, la cual implica espera, observación, escucha y capacidad para asumir la ignorancia.

\section{Ser tolerante}

Se trata de una actitud mental tan consustancial al quehacer médico que a menudo somos inconscientes de su importancia y de cómo determina nuestra actitud y actividad. No es posible ser médico sin ser tolerante. Esperamos ser tolerantes a pesar de las exigencias a menudo desmedidas o de las provocaciones constantes conscientes e inconscientes a que nos someten.

El problema es confundir la tolerancia con la complicidad con aspectos inadecuados o necesidades y exigencias desmedidas por parte del consultante. De ahí que sea tan necesario diferenciar entre la tolerancia basada en la capacidad de entender los sufrimientos del consultante y de soportarlos dentro de nosotros sin escapar o "actuar" (dando prescripciones inadecuadas, consejos o derivaciones improcedentes) para poder ayudar a elaborar y la tolerancia basada en el temor a que el paciente nos agreda en la autoestima, nos desprecie y nos abandone.

Un peligro o deformación de la tolerancia es lo que llamó Balint colusión con el paciente (o connivencia) por miedo a las críticas, temores a las situaciones hostiles, dificultad para oponerse al otro en la relación, temores narcisistas (que prefieran otro profesional, que no hagan comentarios buenos del médico), etc.

\section{Que nos valoren}

Como seres humanos que somos, los médicos no solo deseamos ser útiles a los demás. En el fondo de cada uno de nosotros, incluso de los más desinteresados y esforzados, existe el deseo de que se nos reconozca y que se nos valore, máxime en una profesión como la nuestra, a la que solemos dedicar jornadas de trabajo mayores que las de gran parte de la población.

Pero existen profesionales que acuden a la consulta con una necesidad de valoración tan exagerada que la más mínima contrariedad, frustración u oposición por parte de los compañeros o de los pacientes los hace estallar o descompensarse de forma depresiva o paranoide, y por ello es importante elaborar mínimamente nuestras tendencias narcisistas, que todos poseemos, pero que dependiendo del grado determinan nuestro quehacer profesional.

\section{TEMORES DEL MEDICO}

\section{Errar}

Un médico puede errar el diagnóstico de un paciente, o bien no llegarlo a realizar, sin por ello lesionarle. No obstante, podemos hacer daño con nuestros errores e inadvertencias. Incluso acciones u omisiones dentro de la consulta pueden resultar yatrógenas.

Por otro lado, están los temores o ansiedades persecutorias ante los errores ¿qué pensarán, qué dirán de nosotros? Esto a un nivel más profundo es el temor a la herida en nuestra propia autoestima.

El temor a dañar no siempre es negativo, ya que ese temor nos ayuda a ser más cuidadosos en las exploraciones, tanto físicas como psicológicas. El médico ha de acostumbrarse a afrontarlo y elaborarlo de forma creadora, sin caer en la típica "caracteropatía" del médico "curtido" insensible al dolor ajeno, o en actitudes fóbicas de omitir exploraciones y tratamientos necesarios.

\section{Temor a ser invasivo}

Todo profesional mínimamente sensible siente en alguna ocasión este tipo de temores. Esto puede llevar en el extremo a actitudes de huida ante lo psicológico por la poca preparación para afrontar estos temas que recibimos durante la carrera, o por diversas razones de índole personal. Cuando hablamos o tratamos de 
temas psicológicos nos remontamos siempre a nuestro sistema de referencias, nuestro propio aparato psíquico, por ello, un buen contacto con los propios conflictos y dificultades psicológicas y una adecuada percepción de nuestras ansiedades, frustraciones y limitaciones puede ser el mejor instrumento para poder contactar con los pacientes.

Pero si esas tendencias y esos conflictos se encuentran mínimamente integrados, elaborados en nosotros, podemos disponer de nuestros propios sentimientos, además de nuestro equipamiento científico-intelectual, para discernir hasta qué punto una exploración puede ser en exceso invasiva, vergonzante para un paciente, y hasta qué extremos no. Nuestro instrumento para medir esas variables es nuestra propia capacidad cognitiva: por un lado, nuestros conocimientos y experiencia con respecto a esas técnicas, por otro, nuestros sentimientos y empatía con respecto al consultante.

Para realizar una correcta asistencia, máxime en atención primaria, lo que necesitamos no son tanto protocolos y cuestionarios para interrogar a los pacientes, evitando así ansiedades suplementarias, silencios, momentos de duda o de no saber qué hacer. Esos instrumentos pueden ser útiles, pero solo si se complementan con un dispositivo mucho más fino, delicado y difícil de "mantener a punto": nuestra capacidad de escuchar, observar y esperar.

Indudablemente, también así cometeremos errores, como los comete incluso una madre a propósito de las necesidades de su hijo o bebé: en último extremo, éste no llega a decirle qué es lo que desea o necesita. La madre debe intuirlo y, para ello, no le queda más remedio que intentar imaginar qué tipo de sentimientos le produciría a ella esa situación o por qué sufriría ella en tal o cuál situación. Esa capacidad de imaginar lo que le ocurre al bebé, esa capacidad de fantasear con él y por él, esa capacidad de revérie, como la llamó Bion (1963, 1970), tiene alguna relación con los "instrumentos" que puede utilizar el médico para discernir hasta qué punto una exploración puede ser o no intrusiva, dolorosa o vergonzante para un consultante cualquiera. $Y$ recordemos que, cuando hablamos de exploraciones, nos estamos refiriendo también a las psicosociales, que la mayoría de las veces no han de realizarse de forma activa o intrusiva, sino precisamente sabiendo escuchar, observar e imaginar por el paciente.

\section{Ser poco útil}

El médico no siempre tiene claro lo que es útil para el paciente, y está demostrado en muchos trabajos que lo que el paciente de verdad vive como útil es: poder explicarse, poder ser ayudado a observar y observarse y sentirse contenido en sus ansiedades y temores (Treadway, 1983).

Se trata de un temor lógico en una profesión y una actividad basada precisamente en la ayuda a los demás. El que nuestra acción u omisión pueda resultar poco útil para los consultantes es uno de los temores a los que se enfrenta el médico en cada uno de sus actos profesionales, aunque, como ocurre a menudo, el origen de ese temor suele ser contradictorio. Por un lado, y en unos profesionales más que en otros, lo que infunde temor es la herida a la propia autoestima que significa el verse uno mismo poco útil, no conocedor. Incluso, la herida que significa el que los pacientes se percaten de ello y lo manifiesten. Por otro lado, y generalmente de forma más importante, el fallo que ello implica en nuestra capacidad de ayudar, de expresar la solidaridad humana, motivación tan importante en todos nosotros y tan básica en toda actividad asistencial.

Ese temor a ser poco útil es el que, hipertrofiado y deformado, lleva incluso a la yatrogenia y a la malpraxis. Cuando un médico desconoce aún qué tiene el paciente o duda sobre si tiene o no alguna afección o cuál ha sido en realidad el motivo de su consulta, pocas veces puede resistir el temor a ser considerado (y considerarse) poco útil. $Y$ en ese momento tiende (tendemos todos) a recetar, demandar exploraciones, brindar consejos bienintencionados o seudoexplicaciones nada tranquilizadoras. Suelen ser sistemas poco útiles, tanto para el paciente como para nosotros mismos y para la asistencia, aunque a menudo, dominados por esos temores, por el "qué dirá" el consultante (y por otros tipos de ansiedades), caigamos en su utilización.

El peligro, como decimos, es la yatrogenia y la malpraxis si vamos generalizando esta actitud. Y, desde luego, ansiedades personales y profesionales de todo tipo no nos faltarán para que la generalicemos. Pero es que, además, tales actitudes se basan en una idea equivocada de lo que puede resultar útil para el paciente, y está demostrado (Treadway, 1983; Balint, 1967, 1968; Balint et al 1966, 1973; Marty et al, 1963) que, muy a menudo, lo que de verdad es útil para el paciente, incluso lo que él entiende como útil (Treadway, 1983), es poder explicarse, poder ser ayudado a observar, captar cómo el otro, ante la comunicación de la ansiedad, no tiende a actuar, sentirse contenido en las ansiedades y temores. Por mucho que en las facultades de medicina a menudo nos enseñen una visión de la utilidad y la eficacia, en ocasiones rayan en el productivismo taylorizado. La realidad posterior de la asistencia, y más aún de la asistencia ambulatoria, es así de diferente. Además, no olvidemos que cuando ante las actitudes del paciente temeroso, sufriente, lleno de incertidumbres, nosotros podemos actuar, o no actuar, calmadamente, recogiendo esa ansiedad en nosotros sin responder con nuevas ansiedades personales o con acciones precipitadas. Si podemos reconocer que aún no tenemos datos suficientes, si, llegado el momento de esperar, podemos mostrar nuestra capacidad de hacerlo sin sentirnos por ello desbordados por la ansiedad, estamos también proporcionando otra pauta de aprendizaje que, por mínimamente buena que sea la relación médico-paciente, el consultante va a tender a recoger e interiorizar.

4. No comprender al paciente, ser poco tolerante Si la persona, su actitud en la relación, su enfermedad, o cualquier elemento no son de nuestro agrado (su aseo personal, su forma de expresarse, sus defectos 
personales), es natural que a veces temamos no ser suficientemente tolerantes con el paciente. El poder sentir y soportar este temor es necesario para no caer en los mil sistemas de quitarse al paciente de encima: rechazo, inatención de patologías, adoctrinamiento o hipertrofia del rol apostólico, derivación, etc.

La elaboración de este temor aumentará nuestra tolerancia y capacidad de contención ante personas, conflictos ante los cuales nos encontramos a disgusto o problematizados. Cuando la relación médico-paciente es buena, con el tiempo el paciente enriquece su expresión, sus hábitos higiénicos, e incluso la forma de expresarse, por imitación de modelo y no por imposición y adoctrinamiento.

\section{Que no nos valoren, que nos hieran, que nos hagan sufrir}

Este es uno de los puntos que merece la pena recoger y analizar porque ante la situación sanitaria en nuestro país el temor de los profesionales a la valoración está escindido ¿qué opinión desfavorable teme más el médico que trabaja en los Servicios de Salud: la de los consultantes, la de sus compañeros o la de sus jerarquías?. Todos sabemos que ciertas formas organizativas propuestas para el funcionamiento asistencial desde criterios puramente económicos son perversas y fomentan la perversión de lo que debe ser un equipo asistencial. Esto tiene una influencia negativa sobre cada uno de los componentes de la relación asistencial. Lo que se teme no es tanto el mal-atender o incluso dañar sino, ante todo, que nuestros jefes o superiores se hagan una mala idea de nosotros o no nos valoren suficientemente. Fantasías infantiles de agradar a imagos parentales proyectados en la institución que en muchos casos se combinan con una situación real de sometimiento por inestabilidad de los puestos laborales (interinidad, contrato temporal, etc,).

Esta perversión frecuente que prima la opinión de la jerarquía sobre las actuaciones de los profesionales, basándose en los objetivos "pactados", escinde al profesional en la práctica asistencial.

Todo equipo no democrático, jerarquizado de forma rígida y exagerada o burocratizado, va a tener como consecuencia esa situación que Tizón García llama "perversión organizativa". Puede observarse, por ejemplo, en la necesidad de los inferiores de alcanzar el escalafón por la valoración de los superiores más que por otras motivaciones deontológicas. También pueden apreciarse en otros muchos fenómenos: la necesidad compulsiva de publicar, más que de atender a los pacientes, como conducta de evitación ante el malestar que les provoca la atención clínica por sus dificultades internas para elaborar ansiedades, las continuas carreras por "estar más al día en las publicaciones internacionales" que el compañero, la multiplicación de las jerarquías intermedias (administrativas o funcionales), etc., todo ello producto de la huida del quehacer clínico motivado por necesidades narcisistas (Tizón García, 1988).

Con todo esto parece claro que los factores intrapsíquicos del propio médico son fundamentales para realizar una asistencia o atención clínica mínimamente satisfactoria, tanto para el propio profesional como para el paciente. Para la práctica médica los rasgos de personalidad del propio profesional son de capital importancia, pero ello no es óbice para que se puedan mejorar los rasgos que favorecen una relación positiva con el paciente.

\section{PSICOLOGIA DE LA RELACION ASISTENCIAL, CONTENCION E INTERACCION TERAPEUTICA}

El primer contacto del consultante con el médico o el equipo sanitario ocurre generalmente cuando aquél, sea por temores ante la enfermedad o por los padecimientos que ésta le impone, se encuentra bajo los efectos de la ansiedad. Por ello, es probable que aparezca ante nosotros menos integrado, como más perturbado de lo que en realidad es, con un nivel de integración y de desarrollo personal menor del que en otras ocasiones mostraría. En estos momentos, no tenemos en cuenta que estas personas han pasado, a lo largo de su vida, toda una serie de acontecimientos estresantes (casarse, hijos, pérdidas, sufrimientos, carencias, etc.) sin desmoronarse. Aspectos positivos que siempre hay que explorar en toda entrevista y que haya que señalar como reforzadores.

A menudo, incluso aparecen en los pacientes rasgos que podemos sentir como infantiles, inmaduros; no olvidemos que las enfermedades y las contrariedades importantes tienden a desencadenar en todos los seres humanos tendencias a la regresión. Tendencias más marcadas por la necesidad de ayuda, por la demanda de atención, dependencia, necesidad de castigo, etc. Actitudes que todos nosotros hemos mantenido durante la infancia: período de la vida en el que dependemos hasta los últimos extremos de los que nos rodean y en la cual nuestra capacidad de autonomía está muy reducida.

Este hecho, la regresión, que hace tan diferente la relación que los consultantes establecen con los profesionales que la que establecerían en otras circunstancias, puede tener, simplificando, tres tipos de respuesta en los profesionales:

1) Favorecer el distanciamiento por evitación y huida.

2) Favorecer la dependencia creando en los equipos una situación de ansiedad crónica, en relación con las ansiedades crónicas, no elaboradas, que son transmitidas intensamente por cada paciente a equipos sometidos a gran presión asistencial.

3) Favorecer la relación médico-paciente, para lo cual se debe producir en el médico una actitud de escucha abierta al dolor emocional del consultante. Si el médico puede ofrecerse como receptáculo del exceso de ansiedad que los pacientes no pueden aguantar porque son incapaces de elaborar en ese momento, ya solo con esa actitud proporciona alivios, ayuda y mejoría en su práctica cotidiana, y sobre todo si además sus acciones y palabras ayudan a que los aspectos más sanos del paciente 
puedan aflorar. Una iniciativa sana dispuesta a comprender, elaborar e integrar la situación de sufrimiento ayudará a no cronificar al paciente en las defensas contra la ansiedad.

Ayudándole a verbalizar el dolor o el sufrimiento con una actitud comprensiva hacia él mismo. Esta habilidad de recibir y sostener el dolor y la ansiedad ajenos dentro de uno mismo, sin devolverlo, rechazarlo o actuarlo, es semejante a lo que la madre hace con un bebé. $\mathrm{D}$. W. Winnicott (1955), un pediatra psicoanalizado, que luego llegó a ser uno de los psicoanalistas europeos más influyentes, fue quien más hizo hincapié en estos procesos: en la gran necesidad que tiene el niño pequeño de que la madre le ofrezca su apoyo físico y emocional, lo sostenga en sus necesidades, frustraciones, dolores. Pero no es un mero sostener, sino un contener dentro de nosotros al otro mental y físicamente.

El hecho de que uno de nosotros haya tenido una madre o figura sustitutiva que nos haya contenido bien facilita enormemente nuestro desarrollo psicológico, dándonos la capacidad de mentalización: una moratoria, una cierta espera que facilita la labor de reflexionar y planificar.

El descubrimiento de la contención marcó un hito en la psicología de las relaciones humanas. Este concepto juega un papel importante en las explicaciones de la ayuda psicológica que un equipo sanitario puede prestar en asistencia primaria.

La contención será, pues, ese proceso mediante el cual podemos percibir la ansiedad ajena y propia, notando cómo se remueven en nosotros extractos más profundos, sin pasar a la acción, dándonos por ello un tiempo para la mentalización, reflexión y planificación de cuándo y cómo comenzar a elaborar con el paciente, y secundaria e indirectamente mostrarles un modelo con el que identificarse, lo mismo que ocurre entre el niño y la madre.

Cada vez que el niño llora, la madre se pone ansiosa porque percibe su ansiedad, pero no actúa de inmediato. La madre contiene esa ansiedad propia y se plantea qué es lo que puede estar pasando, si es capaz de sentir, emocionarse, y fantasear con y por el bebé (Bion: "reverie", 1963;). Por ensayo y error, cada vez será más certera en la comprensión del mismo y más contenedora incluso de su propia ansiedad ante los errores para irlos admitiendo y dirigiendo progresivamente.

Isca Salzberger-Wittemberg (1970) recuerda que cuando una persona es receptiva es capaz de escuchar, comprender y aguantar el dolor emocional ajeno. Se genera un proceso dinámico que tiende a desarrollar la relación, los aspectos solidarios (amorosos en un sentido general) de la interacción. Bion lo pone en relación con la idea de continente y contenido. Para el bebé la madre funciona realmente como un continente, una envoltura en la que puede sentirse contenido. A menudo, lo que necesitamos en los momentos de confusión, desesperación o frustración es alguien que puede contenernos, incluso físicamente, mediante el abrazo. Alguien que puede recibirnos en sus brazos o al menos en su mente sin rechazar nuestras manifestaciones, nuestro dolor. Si el otro es capaz de recibir y tolerar los aspectos rechazados de uno mismo, si alguien puede escucharlos, sentirlos y hablar de ellos y "no pasa nada", tal vez no sean tan aterradores, tan dolorosos como uno mismo imagina. Las prácticas conductistas integran procesos de identificación con la actitud contenedora del profesional.

A otro nivel más intrapsíquico diremos que esta relación con una persona comprensiva, que actúa como continente, permite al paciente el contacto con experiencias propias en las que se sintió contenido y recuperar estos aspectos contenedores de él mismo.

Por el contrario, si el equipo de Salud responde de forma inapropiada, no contenedora, esto genera en el consultante la sensación-sentimiento de que tampoco los otros saben "lidiar" con esas emociones, ansiedades y temores que a él le arrastran, y las actitudes regresivas se incrementan.

La capacidad de reverie de Bion, este componente intrapsíquico cognitivo, se basa en la "capacidad de observar y de observarnos observando". Es nuestra tarea contener la situación para poderla descifrar, nombrar y solucionar si parece conveniente y factible hacerlo. Además, el mero hecho de identificar sentimientos y emociones, de saber de dónde vienen y dónde van, de traducirlos en palabras, produce en nosotros mismos y en el consultante una cierta sensación de orden mental, de menor confusión, lo cual es ventajoso siempre.

\section{APOYO PSICOLOGICO EN ATENCION PRIMARIA}

Hablar de psicoterapia en el sentido estricto en Atención Primaria es ilusorio, máxime si se conoce que los psiquiatras en rarísimas ocasiones podemos aplicar técnicas psicoterapéuticas (no olvidemos que el tiempo medio "pactado" en cada revisión psiquiátrica es de 15 minutos). Cualquier psicoterapeuta, de cualquier orientación, necesita un tiempo mínimo de 1/2 a 1 hora y la posibilidad de acortar las revisiones (frecuencia semanal o al menos quincenal).

En este sentido, la única psicoterapia que puede realizar un profesional de la salud es el apoyo terapéutico. Considerada tradicionalmente la psicoterapia de apoyo como una categoría residual pensada para ser prescrita a pacientes no tratables, no había sido objeto de escrutinio conceptual ni de estudios empíricos. A partir de 1986 comienzan a aparecer varios libros y artículos dedicados al tema (Werme, 1984; Winston, 1986, Rockland, 1989; Pinsker, 1991).

\section{Objetivos}

Esta modalidad de terapia intenta ayudar al paciente a mantener o restablecer su nivel de funcionamiento óptimo a pesar de las limitaciones de la enfermedad, su personalidad, sus habilidades naturales o sus circunstancias vitales. En general, este objetivo la diferencia del resto de terapias orientadas a cambios específicos.

Los teóricos de la psicología del "yo" han señalado 
que proporcionar un ambiente de apoyo, escucha empática y actuar como un objeto de identificación seguro y digno de confianza puede llevar a fortalecer el yo, incrementando sus defensas y así favorecer la independencia del paciente.

El apoyo psicológico está indicado en todo tipo de pacientes, en todo tipo de enfermedades, y la duración no está limitada al tiempo de la sesión o a la frecuencia intersesiones, sino que puede adaptarse a las necesidades del paciente, del profesional y de la institución. Alexander fue el primero en estudiar la psicoterapia de apoyo y estableció como base de la misma la importancia de la relación médico-paciente por un lado, y la intervención activa por parte del terapeuta por otro.

El terapeuta debe ser accesible, seguro y capaz de asumir algunas funciones de apoyo (yo auxiliar, superyo auxiliar) a manera de figura parental buena. En una situación terapéutica así, el paciente es capaz de identificarse con el terapeuta y de asimilar las capacidades de funcionamiento óptimo que éste puede tener, de ahí la importancia de saber contener y contenerse por parte del mismo. La utilización de la relación terapéutica desde la perspectiva del paciente para alcanzar una mayor autonomía se asemeja a la independencia que adquiere el niño a medida que va internalizando las figuras parentales. El uso de la figura "maternal" como objeto de idealización por el niño es necesario para que éste alcance un sentido del yo coherente y estable, y por consiguiente una buena autoestima. De forma análoga, permitir al paciente que, durante el tiempo que estime necesario, se vea a sí mismo especularmente en la figura parental idealizada del médico le va a permite creer o estabilizar nuevas estructuras y conductas internas adquiridas.

Muchos pacientes desarrollan una relación dependiente y ambivalente semejante al proceso de individuación-separación en el niño, por eso es tan importante el respeto por parte del terapeuta, de los movimientos de autonomía y de la necesidad de repostar. Las técnicas esenciales: prueba de realidad, reafirmación, clarificación, establecimiento de límites, refuerzo, reestructuración cognitiva, etc., van a ayudar a tal fin. Las interpretaciones, si se realizan, deben ir encaminadas a disminuir la ansiedad y fortalecer las defensas, y en general están desaconsejadas (el material inconsciente puede ser muy ansiógeno y conflictivo).

Se utiliza el material consciente, que no ponga en peligro su autoestima, y todo debe ir encaminado a aliviar al mismo de la tensión y el sufrimiento. En algunos estudios las terapias de apoyo resultan muy eficaces para fortalecer el yo y el funcionamiento individual, y con resultados comparables al resto de las psicoterapias.

\section{BIBLIOGRAFÍA}

1. Balint M. El médico general como psicoterapeuta. En: Balint M, ed. El médico, el paciente y la enfermedad. Buenos Aires: Libros Básicos; 1986. p. 221-244.

2. Balint M. Las sugestiones del paciente y las reacciones del médico. En: Balint M, ed. El médico, el paciente y la enfermedad. Buenos Aires: Libros Básicos; 1986. p. 41-58.

3. Balint M. La particular atmósfera psicológica de la práctica general. En: Balint M, ed. El médico, el paciente y la enfermedad. Buenos Aires: Libros Básicos; 1986. p. 202-218.

4. Balint M. La función apostólica. En: Balint M, ed. El médico, el paciente y la enfermedad. Buenos Aires: Libros Básicos; 1986. p. 273-301.

5. Balint M. El médico y su paciente. En: Balint M, ed. El médico, el paciente y la enfermedad. Buenos Aires: Libros Básicos; 1986. p. 302-316.

6. Balint M. Complicidad en el anonimato. En: Balint M, ed. El médico, el paciente y la enfermedad. Buenos Aires: Libros Básicos; 1986. p. 97-111.

7. Tizón JL. Entrando desde la práctica. En: Tizón JL, ed. Componentes psicológicos de la práctica médica. Barcelona: Doyma; 1988. p. 1-68.

8. Tizón JL. La importancia de lo intrapsíquico para la asistencia médica. En: Tizón JL, ed. Componentes psicológicos de la práctica médica. Barcelona: Doyma; 1988. p. 69-105.

9. Tizón JL. La ansiedad y los mecanismos de defensa. En: Tizón $\mathrm{JL}$, ed. Componentes psicológicos de la práctica médica. Barcelona: Doyma; 1988. p. 107-158.

10. Tizón JL. La atención sanitaria centrada en el consultante. En: Tizón JL, ed. Componentes psicológicos de la práctica médica. Barcelona: Doyma; 1988. p. 159-244.

11. Balint E, Norell JS. Seis minutos para el paciente. Buenos Aires: Paidós; 1979.

12. Balint M, Balint E. Técnicas psicoterapéuticas en medicina. México: Siglo XXI; 1966.

13. Bion WR. Aprendiendo de la experiencia. Buenos Aires: Paidós; 1966.

14. Freud S. La ansiedad y la vida pulsional (La angustia y la vida instintiva). En: Freud S, ed. Obras Completas, II. Madrid: Biblioteca Nueva; 1968.

15. Freud S. Neurosis y psicosis. En: Freud S, ed. Obras Completas, II. Madrid: Biblioteca Nueva; 1968.

16. Freud S. Inhibición, síntoma y angustia. En: Freud S, ed. Obras Completas, II. Madrid: Biblioteca Nueva; 1968.

17. Klein M. Estadios tempranos del conflicto edípico. Contribuciones al psicoanálisis. En: Klein M, ed. Obras completas (Tomo 2). Buenos Aires: Paidós; 1975.

18. Winnicott DW. La familia en la formación del individuo. Buenos Aires: Hormé; 1971.

19. Winnicott DW. El proceso de maduración en el niño. Estudios para una teoría del desarrollo emocional. Barcelona, Laia, 1975. 